\title{
SNMMI Procedure Standard for Scintigraphy for Differentiated Thyroid Cancer
}

Twyla B. Bartel (Chair), DO, FACNM ${ }^{1}$, Samuel Magerefteh ${ }^{2}$, Anca M. Avram, FACNM ${ }^{3}$, Helena R. Balon ${ }^{4}$, Lorraine E. De Blanche, FACNM ${ }^{5}$, Simin Dadparvar, FACR, FACNM ${ }^{6}$, Mickaila Johnston, CDR, MC, USN, FACNM ${ }^{7}$, and Shari Moreau, $\mathrm{CNMT}^{8}$

${ }^{I}$ Global Advanced Imaging, PLLC, Little Rock, Arkansas; ${ }^{2}$ Prohealth Advanced Imaging, Beverly Hills, California; ${ }^{3}$ University of Michigan Medical Center, Ann Arbor, Michigan; ${ }^{4}$ Beaumont Hospital, Royal Oak, Michigan; ${ }^{5}$ Virginia Dallas Department of Nuclear Medicine, Dallas, Texas; ${ }^{6}$ Temple University, Philadelphia, Pennsylvania; ${ }^{7}$ Naval Medical Center, San Diego, California; and

${ }^{8}$ Washington Hospital, Washington, D.C

\section{PREAMBLE}

The Society of Nuclear Medicine and Molecular Imaging (SNMMI) is an international scientific and professional organization founded in 1954 to promote the science, technology, and practical application of nuclear medicine. Its 18,000 members are physicians, technologists, and scientists specializing in the research and practice of nuclear medicine. In addition to publishing journals, newsletters, and books, the SNMMI also sponsors international meetings and workshops designed to increase the competencies of nuclear medicine practitioners and to promote new advances in the science of nuclear medicine.

The SNMMI will periodically define new procedural recommendations for nuclear medicine practice to help advance the science of nuclear medicine and to improve the quality of service to patients. Existing practice guidelines will be reviewed for revision or renewal, as appropriate, on their fifth anniversary or sooner, if indicated.

Each procedural recommendation, representing a policy statement by the SNMMI, has undergone a thorough consensus process in which it has been subjected to extensive review. The SNMMI recognizes that the safe and effective use of diagnostic nuclear medicine imaging requires specific training, skills, and techniques, as described in each document.

These procedural recommendations are an educational tool designed to assist practitioners in providing appropriate care for patients. They are not inflexible rules or requirements of practice and are not intended, nor should they be used, to establish a legal standard of care. For these reasons and those set forth below, the SNMMI cautions against the use of these procedural recommendations in litigation in which the clinical decisions of a practitioner are called into question.

For correspondence or reprints contact: Twyla B. Bartel, Global Advanced Imaging, PLLC, 42 Fontenay Circle, Little Rock, AR 72223.

E-mail: twylabb@hotmail.com

COPYRIGHT (c) 2020 by the Society of Nuclear Medicine and Molecular Imaging. DOI: $10.2967 /$ jnmt.120.243626
The ultimate judgment regarding the propriety of any specific procedure or course of action must be made by the physician in light of all the circumstances presented. Thus, an approach that differs from the procedural recommendations, standing alone, does not necessarily imply that the approach was below the standard of care. To the contrary, a conscientious practitioner may responsibly adopt a course of action different from that set forth in the procedural recommendations when, in the reasonable judgment of the practitioner, such course of action is indicated by the condition of the patient, limitations of available resources, or advances in knowledge or technology subsequent to publication of the procedural recommendations.

The variety and complexity of human conditions make it impossible to always reach the most appropriate diagnosis or to predict with certainty a particular response to treatment. Therefore, it should be recognized that adherence to these procedural recommendations will not ensure an accurate diagnosis or a successful outcome. All that should be expected is that the practitioner will follow a reasonable course of action based on current knowledge, available resources, and the needs of the patient to deliver effective and safe medical care. The sole purpose of these procedural recommendations is to assist practitioners in achieving this objective.

\section{INTRODUCTION}

Surgical histopathology, diagnostic and posttherapy radioiodine (RAI) scintigraphy, and postoperative thyroglobulin ( $\mathrm{Tg}$ ) provide information contributing to differentiated thyroid cancer (DTC) staging, risk stratification, and clinical management. The purpose of this document is to provide the procedure standard on the RAI scintigraphy aspect of DTC management. The addition of SPECT/CT to planar RAI imaging has been shown to reduce equivocal findings and improve staging in these patients. 


\section{GOALS}

The goal of this procedure standard is to assist nuclear medicine practitioners in recommending, performing, interpreting, and reporting the results of scintigraphy for DTC.

\section{DEFINITIONS}

Radioactive iodine (RAI) is taken up by functioning benign or malignant thyroid tissue based on sodium-iodide symporter (NIS) expression.

RAI scintigraphy with ${ }^{131} \mathrm{I}-\mathrm{NaI}$ or ${ }^{123} \mathrm{I}-\mathrm{NaI}$ can be performed after total thyroidectomy and before RAI ablation, after therapeutic ${ }^{131} \mathrm{I}-\mathrm{NaI}$ administration, or as surveillance for identification and localization of regional and distant DTC metastases. The typical images acquired are planar anterior and posterior whole-body along with spot views of the neck and chest and with additional SPECT/CT as clinically indicated.

Radiotheranostics for thyroid cancer integrates diagnostic imaging and therapeutic radionuclides, with ${ }^{131} \mathrm{I}-\mathrm{NaI}$ being the classic example of a radiotheranostic agent for this purpose. This document focuses on the imaging aspect of this equation.

Thyroglobulin $(\mathrm{Tg})$ is a dimeric protein produced by the follicular cells of the thyroid gland, can be elevated in residual thyroid tissue, and is used as a DTC tumor marker after total thyroidectomy and postoperative thyroid remnant ablation.

Tg antibody is a class $\mathrm{G}$ immunoglobulin and can also be elevated in recurrent thyroid cancer.

${ }^{18}$ F-FDG PET may be helpful for detecting recurrent thyroid cancer in cases of a rising serum $\mathrm{Tg}$ and negative radioiodine imaging.

\section{COMMON CLINICAL INDICATIONS}

The common clinical indication for using thyroid scintigraphy as outlined here is for the detection of the presence of and localization of any functioning residual, recurrent, or metastatic DTC. This includes patients shortly after thyroidectomy and before or after ${ }^{131} \mathrm{I}-\mathrm{NaI}$ treatment of iodine-avid tissue as well as for any surveillance.

\section{QUALIFICATIONS AND RESPONSIBILITIES OF PERSONNEL}

\section{A. Physician}

Scintigraphic imaging for DTC should be performed under the supervision of a physician specialized in nuclear medicine and certified by the appropriate board.

\section{B. Technologist}

Scintigraphic imaging for DTC should be performed by a qualified registered or certified nuclear medicine technologist. Refer to the Responsibility and Guidelines for the Nuclear Medicine Technologist for further details.

\section{Medical Physicist}

The medical physicist should be involved in protocol/ image acquisition and processing as necessary including as recommended by the manufacturer.

\section{PROCEDURE}

Also see the SNMMI Procedure Standard for General Imaging.

\section{A. Study Requisition and Appropriateness}

The requisition should include all clinical information about the patient necessary for correct coding of the study. The requisition should also indicate the ability of the patient to cooperate, if there is need for mild sedation or analgesia, and whether the patient needs to be accompanied by a guardian. The examination request should be reviewed by the nuclear medicine staff and as needed by the nuclear medicine physician for appropriateness. The patient should also be contacted by the nuclear medicine department for any prescan instructions (i.e., low iodine diet), to give general information regarding the requested nuclear medicine procedure (i.e., fasting requirements, laboratory to assess pregnancy status, anticipate length of study), and to establish a doctor/patient relationship.

\section{B. Patient Preparation}

Avoid Materials That Can Interfere with Uptake of ${ }^{131} \mathrm{I}$-NaI or ${ }^{123} \mathrm{I}$-NaI. The concentration of radioiodine in functioning benign or malignant thyroid tissue is affected by many interfering factors, and imaging should be delayed for a period long enough to eliminate their competing effects.

- Medications/drugs that may interfere with RAI uptake $(R A I U)$ : Common interfering medications with recommended withdrawal times before RAI administration are listed in Table 1.

- Iodine-containing food and supplements: Optimal preparation for RAI scintigraphy includes a 1- to 2wk low-iodine diet with the goal of minimizing competitive inhibition by stable alimentary iodide $\left({ }^{127} \mathrm{I}\right)$. This is to ensure proper uptake of the radiopharmaceutical by functioning thyroid tissue and to increase imaging sensitivity. Kelp, certain multivitamins, and products made with red food dye number 3 are examples of common iodine-containing ingestible products. A simple practical method of confirming that a lowiodine diet has been followed is by performing a random spot urine iodine measurement (U.S. adult population reference range: $26-705 \mathrm{mcg} / \mathrm{L}$ ). A level $<100 \mathrm{mcg} / \mathrm{L}$ is considered adequate preparation, and $<50 \mathrm{mcg} / \mathrm{L}$ is considered optimal preparation for RAI scintigraphy for DTC. A morning urine specimen provides the most adequate evaluation of recent dietary iodine intake.

- Intravenous contrast: Water-soluble iodinated intravenous contrast must be avoided for 3-4 wk before RAI administration.

Optimize Thyroid-Stimulating Hormone (TSH) Levels. Appropriately elevated TSH levels at the time of postoperative RAI scintigraphic evaluation and therapeutic ${ }^{131} \mathrm{I}-\mathrm{NaI}$ administration are required for increasing the NIS expression in metastatic lesions (and residual thyroid tissue) resulting 
TABLE 1

Representative Drugs/Supplements That Interfere With Radioiodine (in Alphabetical Order)

\begin{tabular}{lc}
\hline \multicolumn{1}{c}{ Name } & Withdrawal time \\
\hline Amiodarone & $3-6 \mathrm{mo}$ \\
Antitussives & $2-4 \mathrm{wk}$ \\
Bromides & $1 \mathrm{wk}$ \\
lodinates ointments & $2-4 \mathrm{wk}$ \\
\hline Levothyroxine (T4) & $4-6 \mathrm{wk}$ \\
Lugol's solution & $2-3 \mathrm{wk}$ \\
\hline Mineral/vitamin supplements & $2-4 \mathrm{wk}$ \\
Nitrates & $1 \mathrm{wk}$ \\
\hline Perchlorate & $1 \mathrm{wk}$ \\
Potassium iodide & $2-3 \mathrm{wk}$ \\
\hline Salicylates (large doses) & $1 \mathrm{wk}$ \\
\hline Steroids & Variable \\
Sulfonamides & $1 \mathrm{wk}$ \\
\hline Triiodothyronine (T3) & $2-3 \mathrm{wk}$ \\
\hline
\end{tabular}

in increased diagnostic sensitivity of RAI scintigraphy and increased radiation-absorbed dose to target lesions. TSH levels $\geq 30 \mathrm{mIU} / \mathrm{L}$ (measured 1-3 d before RAI administration) are considered adequate and can be achieved by either a thyroid hormone withdrawal (THW) (hypothyroid status) or a recombinant human TSH (rhTSH) stimulation during levothyroxine (L-T4) therapy (euthyroid status).

- THW: This consists of L-T4 deprivation for 3 to $4 \mathrm{wk}$ or triiodothyronine (T3) treatment for 4 wk with subsequent T3 discontinuation for 2 wk before RAI scintigraphy.

- rhTSH stimulation: This consists of administration of rhTSH given as 2 intramuscular injections of $0.9 \mathrm{mg}$ on each of 2 consecutive days with RAI or ${ }^{18}$ F-FDG given the next day. rhTSH may be required if the patient cannot be prepared by near-total thyroidectomy, in patients with significant comorbidities in whom prolonged hypothyroidism would represent a risk or cannot be tolerated, in patients with pituitary insufficiency, or in those with isolated TSH deficiency.

- Side effects: The patient should be informed of the potential side effects of rhTSH injection and of hypothyroidism from THW. In order to avoid severely symptomatic, prolonged hypothyroidism, patients may be maintained on T3 until 10-14 d before administration of RAI.

- Considerations for the TSH optimization preparation: The choice of preparation method (THW vs. rhTSH) is a very complex issue and needs to be individualized for each patient. Important considerations include:

1. There is agreement that for normal thyroid tissue (i.e., thyroid remnant), rhTSH and THW stimulation are equivalent, because normal thyroid tissue has constitutive high expression of highly functional Na-I symporters and does not require prolonged TSH stimulation for adequate RAIU and retention.
2. However, metastatic thyroid cancer has lesser density and poorer functionality of Na-I symporters, and therefore, TSH elevation over time (area under the curve of TSH stimulation) is important to promote increased RAIU and retention in tumors. Across 2 clinical studies, rhTSH-stimulated scans failed to detect remnant or cancer localized to the thyroid bed in $17 \%$ of patients and metastatic disease in $29 \%$ in whom it was detected by a scan after L-T4 withdrawal (Thyrogen package insert).

3. The level of Tg elevation after rhTSH stimulation is 3-5 times less than that obtained after THW, which may result in suboptimal evaluation of postoperative disease burden.

Additional Laboratory Values.

- TSH and Tg: If the patient has undergone THW, TSH and $\mathrm{Tg}$ values should be obtained 1-3 d before a diagnostic RAI dose. Knowledge of TSH-stimulated Tg levels is very useful, especially in interpreting negative scintigraphic findings. Typically, a $\mathrm{Tg}$ level of $<1.0$ $\mathrm{ng} / \mathrm{mL}$ indicates remission, whereas a level $>10$ indicates persistent disease. For the rhTSH protocol, Tg should be evaluated at baseline (before rhTSH administration) and at $3 \mathrm{~d}$ after the second dose of rhTSH.

- Anti-Tg antibody: Anti-Tg antibody can falsely elevate or lower Tg levels invalidating the serum Tg measurement. Therefore, $\mathrm{Tg}$ antibody assays must also be obtained in tandem with Tg testing.

Information Pertinent to Performing the Procedure. A summary of information pertinent to performing the procedure is provided in Table 2 .

\section{Precautions/Contraindications}

Pregnancy/Breastfeeding.

- Urine pregnancy test: On the day of scheduled ${ }^{131} \mathrm{I}$ NaI administration for females 12-55 y old, unless there is clear documentation that pregnancy cannot be possible (e.g., previous bilateral oophorectomy), a urine or serum pregnancy test is recommended in addition to clinical history to verify absence of pregnancy.

- Pregnancy after RAI administration: Patients should be advised to avoid pregnancy for at least 6 mo after ${ }^{131} \mathrm{I}-\mathrm{NaI}$ administration.

- Breastfeeding before RAI administration: To allow for breast tissue involution and minimize ${ }^{131} \mathrm{I}-\mathrm{NaI}$ uptake and radiation-absorbed dose to the maternal breast as well as to prevent the nursing child from ingesting radioactive breast milk, breastfeeding should be discontinued for at least $6 \mathrm{wk}$ (but preferably for 3-6 mo) before RAI administration.

- Breastfeeding after RAI administration: After ${ }^{131} \mathrm{I}-\mathrm{NaI}$ administration, breastfeeding must be discontinued. It can be resumed after the birth of another child. If ${ }^{123} \mathrm{I}-\mathrm{NaI}$ is given, breastfeeding can be resumed $72 \mathrm{~h}$ later. For ${ }^{18} \mathrm{~F}-$ FDG, breastfeeding should be discontinued for $4 \mathrm{~h}$. 


\begin{tabular}{|c|c|}
\hline Topic & Action/information needed \\
\hline Radioiodine-interfering materials & $\begin{array}{l}\text { Avoid and obtain history of (e.g., medications, intravenous contrast [especially as a part } \\
\text { of a CT exam]) }\end{array}$ \\
\hline lodine intake & Compliance with low-iodine diet \\
\hline TSH & Appropriate TSH level \\
\hline Stimulation & Preparation with THS versus rhTSH \\
\hline Surgery & $\begin{array}{l}\text { Surgical information (e.g., total/subtotal thyroidectomy vs. lobectomy, extent of } \\
\text { cervical compartments dissected) }\end{array}$ \\
\hline Histopathology & $\begin{array}{l}\text { Information on presence/absence of capsular or angiolymphatic invasion, extrathyroidal } \\
\text { extension, surgical margin status, presence/extent of lymph node metastases, and } \\
\text { level of cervical compartments involved }\end{array}$ \\
\hline Imaging & Results of prior scintigraphy or other pertinent imaging procedures \\
\hline RAl treatments & Information on any prior RAl treatments \\
\hline Physical & Physical exam findings \\
\hline Menstruation/lactation & $\begin{array}{l}\text { Menstrual and lactation history, negative serum pregnancy test before RAI administration } \\
\text { if needed }\end{array}$ \\
\hline
\end{tabular}

\section{Radiopharmaceuticals and Dosage}

The following are recommended diagnostic imaging dosages.

Oral ${ }^{131}$ I-NaI. For diagnostic imaging, 37-148 MBq (1-4 $\mathrm{mCi}$ ) are given, with many preferring a range of 37-74 $\mathrm{MBq}(1-2 \mathrm{mCi})$ because of data suggesting that stunning (decreased uptake of the therapy dose of ${ }^{131} \mathrm{I}-\mathrm{NaI}$ by residual functioning thyroid tissue or tumor due to cell death or dysfunction caused by the activity administered for diagnostic imaging) is less likely at the lower administered activity. However, stunning may not influence the outcome of treatment. The method of TSH stimulation also needs to be considered in deciding the activity used for diagnostic ${ }^{131} \mathrm{I}-\mathrm{NaI}$ scintigraphy, usually as: $37-74 \mathrm{MB} 1$ (1-2 $\mathrm{mCi})$ if the patient is hypothyroid and 111-148 MBq (3-4 mCi) if a rhTSH-stimulation protocol was followed. There is no consensus practice parameter for weight-based administration for children.

Oral ${ }^{123} \mathrm{I}-\mathrm{NaI}$. The typical administered dosage for diagnostic imaging is between 74 and $148 \mathrm{MBq}(2-4 \mathrm{mCi})$. As with ${ }^{131} \mathrm{I}-\mathrm{NaI}$, the ${ }^{123} \mathrm{I}-\mathrm{NaI}$ administered should take into consideration the method of TSH stimulation, typically the lower end of the activity range if the patient is hypothyroid and upper if rhTSH stimulation was followed. There is no consensus practice parameter for weight-based administration for children.

${ }^{18} \mathrm{~F}$-FDG. The typical administered dosage for oncology is $370-740 \mathrm{MBq}(10-20 \mathrm{mCi})$. ${ }^{18} \mathrm{~F}-\mathrm{FDG}$ may be used to identify tumors that are not detected with RAI. These are usually less well-differentiated tumors $\left({ }^{18} \mathrm{~F}-\mathrm{FDG}-\right.$ positive, radioiodine-negative) and are less likely to respond to ${ }^{131} \mathrm{I}-$ NaI treatment. These tumors may be more aggressive; may have a less favorable prognosis; and may be amenable to surgical resection, external radiation, or embolization. Imaging with ${ }^{18} \mathrm{~F}$-FDG is more sensitive when the serum TSH is elevated (THW or rhTSH stimulation).

\section{E. Imaging}

Clinical Settings for Imaging.

- Post-thyroidectomy, pre-RAI ablation imaging: Nuclear medicine physicians are divided as to the need for preablation imaging. The American Thyroid Association (ATA) guidelines recommend that a postoperative diagnostic RAI scan may be useful when the extent of the thyroid remnant or residual disease cannot be accurately ascertained from the surgical report or neck ultrasonography and when the results may alter the decision to treat or the activity of RAI that is to be administered. Despite differing practices regarding preablation diagnostic RAI imaging, one must recognize that the following may be uncovered or useful:

1. Diagnostic RAI scintigraphy may reveal unexpected iodine-avid metastatic disease in $22 \%-35 \%$ cases and change management in approximately $30 \%-50 \%$ cases as compared with an imaging strategy that does not include diagnostic scintigraphy.

2. Approximately $1 \%$ of the time, the thyroidectomy is truly total, and if there are no remnants or other foci of iodine-avid tissue on the scan, then giving radioiodine would not be indicated. However, in high-risk patients, treatment of occult metastases may be warranted.

3. The scan is useful in helping to determine the ${ }^{131} \mathrm{I}-$ $\mathrm{NaI}$ dosage for ablation or therapy. Larger therapeutic RAI activities are usually given for treatment if regional or distant metastases are detected on the preablation scan.

4. Distant metastases in the brain or spinal cord may require preradiation corticosteroids to avoid complications caused by radiation-induced swelling.

5. Identification and localization of abnormal foci on planar imaging may be enhanced by concomitant SPECT/CT imaging.

- Post-thyroidectomy, post-RAI ablation imaging

- Post-thyroidectomy/post-RAI ablation imaging for surveillance: Scintigraphy for surveillance is tailored per the risk stratification of the patient and is an ongoing 
dynamic process. In general, a low-risk patient may not require surveillance, but it is recommended for intermediate to high risk for recurrent DTC and for those with rising $\mathrm{Tg}$ levels and a negative cervical ultrasound.

\section{Instrumentation.}

- ${ }^{131}$ I-NaI: A large field-of-view dual-head $\gamma$-camera fitted with a high-energy parallel-hole collimator is used. A $15 \%-20 \%$ window is centered on the $364-\mathrm{keV}$ photopeak.

- ${ }^{123}$ I-NaI: A low- or medium-energy collimator is used depending on the manufacturer's specifications. A $15 \%-$ $20 \%$ window is centered on the $159-\mathrm{keV}$ photopeak.

- ${ }^{18}$ F-FDG: Follow a usual PET/CT oncology protocol.

\section{Patient Maneuvers.}

- Clearance of confounding physiologic activity: The patient should drink a large glass of water or chew and swallow crackers before each set of images to clear physiologic pharyngeal or esophageal activity.

- Imaging position: The patient should lie supine on an imaging table with the neck slightly extended. Include the chin and arms in the field of view.

Timing.

- 131I-NaI: Preablation and surveillance images are obtained between 24 and $72 \mathrm{~h}$ after RAI administration (24-h images may not have clearly defined activity, thus the patient may need to be brought back at 48-72 h to improve lesion detection repeat imaging to allow an improved target to background ratio). Post-RAI ablation images can be obtained 2-7 d after treatment.

- 123I-NaI: Preablation or surveillance images are obtained 6-24 h after administration of this radiopharmaceutical. Some prefer ${ }^{123} \mathrm{I}-\mathrm{NaI}$ as images are of higher quality than with ${ }^{131} \mathrm{I}-\mathrm{NaI}$ and stunning may be prevented, but cost or availability may be a limiting factor for ${ }^{123} \mathrm{I}$.

- ${ }^{18}$ F-FDG: Images are acquired approximately $60 \mathrm{~min}$ after injection of the radiopharmaceutical. When there is suspicion that the ${ }^{131} \mathrm{I}-\mathrm{NaI}$ scan will be negative or have low sensitivity, an ${ }^{18} \mathrm{~F}$-FDG scan should be performed while TSH levels are elevated (THW or rhTSH protocol). Koranda et al. demonstrated that when the TSH level is stimulated to $>30 \mathrm{mU} / \mathrm{L}$ in patients with radioiodine-negative scans, a large number of cases were true-positive on ${ }^{18} \mathrm{~F}$-FDG $\mathrm{PET} / \mathrm{CT}$ for detecting recurrent/metastatic disease.

Acquisition.

- Whole-body scan: Anterior and posterior planar parallel-hole collimator $\gamma$-camera images from the top of the skull through the femurs are obtained with a scan speed of $8 \mathrm{~cm} / \mathrm{min}$ to $10 \mathrm{~cm} / \mathrm{min}$ with a $256 \times 256$ matrix. Longer acquisition times may be helpful for images obtained more than $3 \mathrm{~d}$ after administration of ${ }^{131} \mathrm{I}$ NaI. A $256 \times 1,024$ matrix may be used for ${ }^{123}$ I-NaI.
- Spot images: Static images should be acquired for 20 min using a $256 \times 256$ matrix per view to include the nasopharynx, thyroid bed, or chest. These images may improve lesion detection.

- Pinhole images: Further pinhole images of selected areas may be acquired as deemed necessary for single photon emitters. These images may improve lesion detection.

- Markers: In the neck, radioactive anatomic markers may be helpful in differentiating between normal residual thyroid tissue, salivary gland uptake, residual thyroid cancer, and lymph node metastasis.

- SPECT/CT: This is helpful for more accurate anatomic lesion localization and especially for identifying lymph nodes in the neck, differentiating mediastinal versus lung uptake, or evaluating for bone metastases. SPECT/CT is preferred over planar imaging to anatomically localize concerning areas of uptake seen on the whole-body RAI scan. One study has shown that diagnostic RAI scans with SPECT/CT performed after total thyroidectomy detected regional metastases in $35 \%$ of patients and distant metastases in $8 \%$. This resulted in a change in clinical management in approximately $30 \%$ of patients as compared with a management strategy based on surgical pathology alone. If available, SPECT/CT imaging should be performed with an axial field of view extending from the skull base to the diaphragm. In addition, all foci of abnormal activity seen on planar images outside the neck and chest that do not conform to a physiologic distribution should be further evaluated with SPECT/CT. The patient is imaged with arms down and without immobilizers. Imaging is performed on a hybrid dual-head $\gamma$-camera with an inline CT scanner. The following are recommended CT image parameters: $130 \mathrm{kVp}, 80 \mathrm{mAs}, 3 \mathrm{~mm}$ collimation, 0.8 pitch (CT reconstruction is performed at $5 \mathrm{~mm}$ slice). The following are SPECT image parameters: 64 projections, $128 \times 128$ matrix, 20 s/projection, noncircular orbit over $360^{\circ}$ (tomographic images are reconstructed using 3-dimensional ordered-subset expectation maximization iterative reconstruction [8 iterations, 4 subsets], and a CT-based attenuation correction algorithm was applied).

- Flood source: An image obtained with a flood source may be considered to outline body contour.

- 24-h neck uptake/residual fraction: Quantitative measurement of RAIU in the neck is often helpful in determining the mass of remaining thyroid tissue or tumor and is usually acquired at $24 \mathrm{~h}$ after administration of ${ }^{123} \mathrm{I}-\mathrm{NaI}$ or ${ }^{131} \mathrm{I}-\mathrm{NaI}$. The desired value after near-total or total thyroidectomy is $0.5 \%-5 \%$. The technique is as follows:

1. Uptake is typically measured with $25-30 \mathrm{~cm}$ between the face of the crystal and the area(s) of interest. 
2. One example among variable techniques using an uptake probe and software is as follows. Acquire counts for $1 \mathrm{~min}$ for each of the following: over the thyroid bed, patient's thigh (body background), room background, and a calibrated standard (radiopharmaceutical source identical to that administered to the patient) contained in a neck phantom.

3. The 24-h RAIU can then be calculated as:

$$
\frac{\text { Neck counts }- \text { thigh counts }}{\text { Phantom count }- \text { background }} \times 100 \%
$$

- ${ }^{18} F-F D G$ PET/CT: Follow the usual PET/CT oncology protocol. Acquisition should be in the $3 \mathrm{D}$ mode.

\section{F. Interpretation Criteria}

Physical Examination. An adequate physical examination and history should be obtained. Palpable soft tissue in the neck should be correlated with scintigraphic findings.

Thyroid Bed Activity. Particular attention should be paid to any activity in the thyroid bed. Planar images may not differentiate between thyroid bed residual normal thyroid tissue (i.e., thyroid remnants) versus thyroid malignancy. Lateral and oblique planar views or preferably SPECT/CT may be useful in this case to help separate thyroid bed activity from adjacent lymph node activity.

Image Correlation. Findings on physical examination and scintigraphy should be correlated with any additional imaging if available (i.e., CT, MR, ultrasound, other nuclear medicine studies).

\section{DOCUMENTATION/REPORTING}

For general recommendations on all nuclear medicine reports, see the SNMMI Procedure Standard for General Imaging and the American College of Radiology Practice Guideline for Communication: Diagnostic Radiology.

\section{A. Indications}

The report should briefly summarize the reason for the examination, pertinent medical or surgical history, and the results of any relevant laboratory tests or prior imaging studies.

\section{B. Technique}

The report should include the name of the radiopharmaceutical administered, the dosage, and the scanning protocol.

\section{Findings}

The report should include the location and character of any abnormal uptake, comparison with the results of prior imaging studies (if pertinent or available), and any pertinent additional CT findings (if CT was performed with SPECT). If obtained, the quantitative $24-\mathrm{h}{ }^{123} \mathrm{I}-\mathrm{NaI} /{ }^{131} \mathrm{I}-\mathrm{NaI}$ uptake value should also be reported along with a qualitative estimate of the size, activity, and location of any areas of uptake that correspond to any functioning normal or abnormal thyroid tissue.

\section{Impression}

The impression should include conclusions, diagnoses, or differential diagnoses to answer questions posed by the referring clinician or team or to answer any unexpected findings, any recommendations for further work-up.

\section{QUALITY CONTROL AND IMPROVEMENT}

See the SNMMI Procedure Standard for General Imaging for general recommendations.

\section{A. Possible Sources of Error}

- Local contamination (clothing, skin, hair, collimator, imaging table)

- Esophageal activity

- Asymmetric salivary gland uptake

- Breast uptake

- Thymic uptake

- Ectopic thyroid tissue

- Uptake by nonthyroid neoplasms

- Inadequate patient preparation

\section{SAFETY, INFECTION CONTROL, AND PATIENT EDUCATION CONCERNS}

See the SNMMI Procedure Standard for General Imaging for general recommendations.

TABLE 3

Radiation Dosimetry for Adults

\begin{tabular}{|c|c|c|c|}
\hline Radiopharmaceuticals & $\begin{array}{l}\text { Administered activity } \\
(\mathrm{MBq}[\mathrm{mCi}])\end{array}$ & $\begin{array}{l}\text { Organ Receiving largest radiation } \\
\text { dose (mGy/MBq }[\mathrm{rad} / \mathrm{mCi}])\end{array}$ & $\begin{array}{l}\text { Effective dose }(\mathrm{mSv} / \mathrm{MBq} \\
[\mathrm{rem} / \mathrm{mCi}])\end{array}$ \\
\hline${ }^{18} \mathrm{~F}-\mathrm{FDG}$ & $370-740$ intravenously $(10-20)$ & 0.15 bladder wall $(0.56)$ & $0.019(0.07)$ \\
\hline $\begin{array}{c}\mathrm{Na}^{123} \text { iodide }(0 \% \\
\text { thyroid uptake) }\end{array}$ & $74-148$ by mouth $(2-4)$ & 0.097 bladder wall $(0.36)$ & $0.010(0.039)$ \\
\hline $\begin{array}{l}\mathrm{Na}^{131} \text { I iodide }(0 \% \\
\text { thyroid uptake) }\end{array}$ & $37-148$ by mouth (1-4) & 0.66 bladder wall $(2.4)$ & $0.058(0.21)$ \\
\hline
\end{tabular}

https://www.doseinfo-radar.com. Accessed August 18, 2020.

International Commission on Radiological Protection. Radiation Doses to Patients from Radiopharmaceuticals. New York, NY: Elsevier. 2008.

Delbeke D, Coleman RE, Guiberteau MJ, et al. Procedure guideline for tumor imaging with ${ }^{18}$ F-FDG PET/CT 1.0. J Nucl Med 2006; 47:885-895. 


\section{RADIATION SAFETY IN IMAGING}

See the SNMMI Procedure Standard for General Imaging for general recommendations. It is the position of SNMMI that exposure to ionizing radiation should be at the minimum level (ALARA: as low as reasonably achievable) needed to obtain a diagnostic examination. Radiation dosimetry for adults is presented in Table 3 .

\section{ACKNOWLEDGMENTS}

The Committee on SNMMI Procedure Standards consists of the following individuals: Dominique Delbeke, MD (Chair) (Vanderbilt University Medical Center, Nashville, TN); Helena Balon, MD (Beaumont Health System, Royal Oak, MI); Twyla B. Bartel, DO, MBA (Global Advanced Imaging, PLLC, Little Rock, AR); Pradeep Bhambhvani, MD (The University of Alabama at Birmingham, Birmingham, AL); David Brandon, MD (Emory University/Atlanta VA Medical Center, Atlanta, GA); Vasken Dilsizian, MD (University of Maryland Medical Center, Baltimore, MD); Kevin J. Donohoe, MD (Beth Israel Deaconess Medical Center, Boston, MA); Saeed Elojeimy, MD, PhD (University of New Mexico, Albuquerque, NM); James R. Galt, PhD (Emory University Hospital, Atlanta, GA); Michael L. Goris, MD, PhD (Stanford, CA); Bennett S. Greenspan, MD, MS (Medical College of Georgia/Augusta University, Augusta, GA); Jay A. Harolds, MD (University of Oklahoma Health Sciences Center, Edmond, OK); Arnold F. Jacobson, MD, PhD (Diagram Consulting, Kihei, HI); Laurel Martell, BS, CNMT, RT (N)(CT) (Brigham and Women's Hospital, North Easton, MA); J. Anthony Parker, MD, PhD (Beth Israel Deaconess Medical Center, Boston, MA); Heiko Schöder, MD (Memorial Sloan Kettering Cancer Center, New York, NY); Barry Shulkin, MD, MBA (St. Jude Children's Research Hospital, Memphis, TN); Michael G. Stabin, $\mathrm{PhD}$ (Vanderbilt University, Nashville, TN); and Mark Tulchinsky, MD, FACNM, CCD (Penn State Health, Milton S. Hershey Medical Center, Hershey, PA).

\section{BIBLIOGRAPHY}

1. ACR practice guidelines for imaging pregnant or potentially pregnant adolescents and women with ionizing radiation. 2018. ACR website. https://www.acr.org/-/media/ ACR/Files/Practice-Parameters/Pregnant-Pts.pdf?la=en. Accessed July 28, 2020.

2. ACR-SPR technical standard for diagnostic procedures using radiopharmaceuticals. 2016. ACR website. https://www.acr.org/-/media/ACR/Files/PracticeParameters/Radiopharmaceuticals.pdf. Accessed July 28, 2020.

3. Avram AM. Radioiodine scintigraphy with SPECT/CT: an important diagnostic tool for staging and risk stratification. In: Thyroid Cancer: A Comprehensive Guide To Clinical Management. 3rd ed. New York, NY: Springer; 2016:215-223.

4. Avram AM, Fig LM, Frey KA, et al. Preablation ${ }^{131}$ I scans with SPECT/CT in postoperative thyroid cancer patients: what is the impact on staging? J Clin Endocrinol Metab. 2013;98:1163-1171.

5. Balon HR, Meier DA, Charkes ND, Royal HD, Sarkar SD, Donohoe KJ. Society of Nuclear Medicine procedure guidelines for thyroid uptake measurement version 3.0. 2006. Amazonaws website. https://s3.amazonaws.com/rdcms-snmmi/ files/production/public/docs/Thyroid\%20Uptake\%20Measure\%20v3\%200.pdf. Accessed July 28, 2020.

6. Baum RP. Therapeutic Nuclear Medicine. Berlin, Germany: Springer; 2014

7. Chen $\mathrm{S}, \mathrm{Li} \mathrm{N}, \mathrm{Li} \mathrm{X}$, et al. $74 \mathrm{MBq}{ }^{131}$ I for diagnostic scan can decrease the uptake of ${ }^{131} \mathrm{I}$ by thyroid remnants or metastases, the thyroid stunning exists. $Q \mathrm{~J}$ Nucl Med Mol Imaging. 2015;59:455-461.
8. Chin BB, Patel P, Cohade C, et al. Recombinant human thyrotropin stimulation of fluoro-D-glucose positron emission tomography uptake in well-differentiated thyroid carcinoma. J Clin Endocrinol Metab. 2004;89:91-95.

9. Choi SJ, Jun KP, See SS, et al. Clinical usefulness of F-18 FDG PET/CT in papillary thyroid cancer with negative radioiodine scan and elevated thyroglobulin level or positive anti-thyroglobulin antibody. Nucl Med Mol Imaging. 2016;50:130-136.

10. Dilsizian V, Metter D, Palestro C, et al. Advisory committee on medical uses of isotopes (ACMUI) sub-committee on nursing mother guidelines for the medical administration of radioactive materials. 2019. NRC website. https://www.nrc.gov/ docs/ML1803/ML18033B034.pdf. Accessed July 28, 2020.

11. Haugen BR, Alexander EK, Bible KC, et al. 2015 American Thyroid Association management guidelines for patients with thyroid nodules and differentiated thyroid cancer: The American Thyroid Association guidelines task force on thyroid nodules and differentiated thyroid cancer. Thyroid. 2016;26:1-133.

12. Dam HQ, Kim SM, Lin HC, et al. ${ }^{131}$ I therapeutic efficacy is not influenced by stunning after diagnostic whole-body scanning. Radiology. 2004;232:527-533.

13. de Geus-Oei LF, Oei H-Y, Hennemann G, et al. Sensitivity of ${ }^{123}$ I whole-body scanning and thyroglobulin in the detection of metastases or recurrent differentiated thyroid cancer. Eur J Nucl Med Mol Imaging. 2002;29:768-774.

14. Grant FD, Treves ST. Thyroid. In: Pediatric Nuclear Medicine and Molecular Imaging. 4th ed. New York, NY: Springer; 2014:99-129.

15. Heston TF, Wahl R. Molecular imaging in thyroid cancer. Cancer Imaging. 2010;10:1-17.

16. ICRP. Radiation dose to patients from radiopharmaceuticals: addendum 3 to ICRP Publication 53-ICRP Publication 106. Approved by the Commission in October 2007. Ann ICRP. 2008;38:1-197.

17. Iwata M, Kasagi K, Misaki T, et al. Comparison of whole-body ${ }^{18} \mathrm{~F}-\mathrm{FDG}$ PET, ${ }^{99 \mathrm{~m} T c-M I B I}$ SPECT, and post-therapeutic ${ }^{131} \mathrm{I}-\mathrm{Na}$ scintigraphy in the detection of metastatic thyroid cancer. Eur J Nucl Med Mol Imaging. 2004;31:491-498.

18. Jo K, Lim DJ. Clinical implications of anti-thyroglobulin antibody measurement before surgery in thyroid cancer. Korean J Intern Med. 2018;33:1050-1057.

19. Kang SW, Yap ZZ, Lee CR, et al. Pattern of urine iodine excretion with low iodine diet during preparation for radioactive iodine ablation in patients with thyroid cancer. Head Neck. 2019;41:381-387.

20. Koranda P, Polzerova H, Henzlova L, et al. TSH-stimulated 18F FDG PET/CT in the diagnosis of recurrent/metastatic radioiodine-negative differentiated thyroid carcinomas. J Nucl Med. 2013;54(suppl 2):309.

21. Kowalska A, Palyga I, Gasior-Perczak D. The cut-off level of recombinant human TSH-stimulated thyroglobulin in the follow-up of patients with differentiated thyroid cancer. PLoS One. 2015;10: e0133852.

22. Lakshmanan M, Schaffer A, Robbins J, et al. A simplified low-iodine diet in I-131 scanning and therapy of thyroid cancer. Clin Nucl Med. 1988; 13:866-8. 209.

$\mathrm{Li} \mathrm{JH}, \mathrm{He} \mathrm{ZH}$, Bansal V, et al. Low iodine diet in differentiated thyroid cancer: a review. Clin Endocrinol (Oxf). 2016;84:3-12.

23. Kulkarni K, Atkins FB, Van Nostrand D. The utility of SPECT-CT in differentiated thyroid cancer. In: Thyroid Cancer: A Comprehensive Guide to Clinical Management. 3rd ed. New York, NY: Springer; 2016: 205-214.

24. Liu H, Wang X, Yang R, et al. Recent development of nuclear molecular imaging in thyroid cancer. BioMed Res Int. 2018:2149532.

25. Liu Y. The role of ${ }^{18}$ F-FDG PET/CT in the follow-up of well-differentiated thyroid cancer with negative thyroglobulin but positive and/or elevated antithyroglobulin antibody. Nucl Med Commun. 2016;37:577-582.

26. Mazzaferri EL, Amdur RJ. Essentials of Thyroid Cancer Management. Berlin, Germany: Springer Science and Business Media; 2006.

27. McDougall IR. $74 \mathrm{MBq}$ radioiodine ${ }^{131} \mathrm{I}$ does not prevent uptake of therapeutic doses of ${ }^{131} \mathrm{I}$ (i.e. it does not cause stunning) in differentiated thyroid cancer. Nucl Med Commun. 1997;18:505-512.

28. McDougall IR, Iagaru A. Thyroid stunning: fact or fiction? Semin Nucl Med. 2011;41:105-112.

29. Mettler FA, Guiberteau MJ. Essentials of Nuclear Medicine Imaging. New York, NY: Elsevier Health Sciences; 2018.

30. Padovani RP, Kasamatsu TS, Nakabashi CCD, et al. One month is sufficient for urinary iodine to return to its baseline after the use of water-soluble iodinated contrast agents in post-thyroidectomy patients requiring radioiodine therapy. Thyroid. 2012;22:926-930.

31. Palmedo H, Bucerius J, Joe A. Integrated PET/CT in the differentiated thyroid cancer: diagnostic accuracy and impact on patient management. J Nucl Med. 2006;47:616-624.

32. Park HM, Park YH, Zhou XH. Detection of thyroid remnant/metastases without stunning: an ongoing dilemma. Thyroid. 1997;7:277-280.

33. Plotkin M, Hautzel H, Krause BJ, et al. Implication of 2-18fluoro-2-deoxyglucose positron emission tomography in the follow-up of Hurthle cell thyroid cancer. Thyroid. 2002;12:155-161.

34. Prestwich RJ, Viner S, Gerrard G, et al. Increasing the yield of recombinant thyroidstimulating hormone-stimulated 2-(18-fluoride)-flu-2-doxy-D-glucose positron emission tomography-CT in patients with differentiated thyroid carcinoma. Br J Radiol. 2012;85:e805-e813. 
35. Robbins RJ, Chon JT, Fleisher M, et al. Is the serum thyroglobulin response to recombinant human thyrotropin sufficient, by itself, to monitor for residual thyroid carcinoma? J Clin Endocrinol Metab. 2002;87:3242-3247.

36. Roman SA, Sosa JA, Solorzano CC. Management of Thyroid Nodules and Differentiated Thyroid Cancer. Berlin, Germany: Springer; 2017.

37. Sarkar SD, Kalapparambath TP, Palestro CJ. Comparison of ${ }^{123} \mathrm{I}$ and ${ }^{131} \mathrm{I}$ for whole-body imaging in thyroid cancer. J Nucl Med. 2002;43:632-634.

38. Sawka AM, Ibrahim-Zada I, Galacgac P, et al. Dietary iodine restriction in preparation for radioactive iodine treatment or scanning in well-differentiated thyroid cancer: a systematic review. Thyroid. 2010;20:1129-1138.

39. Sherman SI, Tielens ET, Sostre S, et al. Clinical utility of post-treatment radioiodine scans in the management of patients with thyroid carcinoma. J Clin Endocrinol Metab. 1994;78:629-634.

40. Shiga T, Tsukamoto E, Nakada K, et al. Comparison of ${ }^{18} \mathrm{~F}-\mathrm{FDG},{ }^{131} \mathrm{I}-\mathrm{Na}$, and ${ }^{201} \mathrm{Tl}$ in diagnosis of recurrent or metastatic thyroid carcinoma. J Nucl Med. 2001;42:414-419.

41. Sisson JC. Selection of the optimal scanning agent for thyroid cancer. Thyroid. 1997;7:295-302.

42. Song H, Mosci C, Akatsu H, et al. Diagnostic ${ }^{123} \mathrm{I}$ whole body scan prior to ablation of thyroid remnant in patients with papillary thyroid cancer: implications for clinical management. Clin Nucl Med. 2018;43:705-709.

43. Stangierski A, Kaznowski J, Wolinski K, et al. The usefulness of fluorine-18 fluorodeoxyglucose PET in the detection of recurrence in patients with differentiated thyroid cancer with elevated thyroglobulin and negative radioiodine whole body scan. Nucl Med Commun. 2016;37:935-938.

44. Thyrogen: highlights of prescribing information [package insert]. Sanofi website. http://products.sanofi.us/Thyrogen/thyrogen.pdf. Accessed August 18, 2020

45. Treves ST, Gelfand MJ, Fahey FH, et al. 2016 update of the North American consensus guidelines for pediatric administered radiopharmaceutical activities. J Nucl Med. 2016;57:15N-18N.

46. Urhan M, Dadparvar S, Mavi A, et al. Iodine-123 as a diagnostic imaging agent in differentiated thyroid carcinoma: a comparison with iodine-131 post-treatment scanning and serum thyroglobulin measurement. Eur J Nucl Med Mol Imaging. 2007;34:1012-7.

47. Walrand S, Hesse M, Jamar F. Statistical and radiobiological analysis of the so-called thyroid stunning. EJNMMI Res. 2015;5:67.

48. Wang W, Larson SM, Fazzari M, et al. Prognostic value of $\left[{ }^{18} \mathrm{~F}\right]$ fluorodeoxyglucose positron emission tomographic scanning in patients with thyroid cancer. J Clin Endocrinol Metab. 2000;85:1107-1113.

49. Wiebel JL, Esfandiari NH, Papaleonitiou M, et al. Evaluating positron emission tomography use in differentiated thyroid cancer. Thyroid. 2015;25:10261032 .

50. Wong KCW, Ng TY, Yu KS, et al. The use of post-ablation stimulated thyroglobulin in predicting clinical outcomes in differentiated thyroid carcinoma: what cut-off values should we use? Clin Oncol (R Coll Radiol). 2019;31: e11-e20.

51. Wong KK, Gandhi A, Viglianti BL, et al. Endocrine radionuclide scintigraphy with fusion single photon emission computed tomography/computed tomography. World J Radiol. 2016;8:635-655.

52. Yen TC, Lin HD, Lee $\mathrm{CH}$, et al. The role of technetium-99m-sestamibi wholebody scans in diagnosing metastatic Hurthle cell carcinoma of the thyroid gland after total thyroidectomy: a comparison with iodine-131 and thallium-201 whole-body scans. Eur J Nucl Med. 1994;21:980-983.

53. Ziessman HA, O’Malley JP, Thrall JH. Nuclear Medicine: The Requisites. New York, NY: Elsevier Health Sciences; 2014.

54. Zilioli V, Peli A, Panarotto MB, et al. Differentiated thyroid carcinoma: incremental diagnostic value of ${ }^{131}$ I SPECT/CT over planar whole-body scan after radioiodine therapy. Endocrine. 2017;56:551-559.

\section{APPROVAL}

The Board of Directors of the SNMMI approved version 4.0 at the SNMMI Mid-Winter Meeting in January 2020. 